\title{
The Prognostic Role of Ventilatory Inefficiency and Exercise Capacity in Idiopathic Pulmonary Fibrosis
}

\author{
Baruch Vainshelboim PhD, Jose Oliveira PhD, Benjamin Daniel Fox MBBS, and \\ Mordechai Reuven Kramer MD
}

\begin{abstract}
BACKGROUND: Idiopathic pulmonary fibrosis (IPF) is a chronic, progressive, and fatal interstitial lung disease associated with poor prognosis and limited effective treatment options. Reliable predictors of outcome in daily clinical practice are needed to determine high-risk patients for urgent lung transplantation referral. This study aimed to identify practical prognostic predictors of mortality using cardiopulmonary exercise testing (CPET) in IPF subjects. METHODS: Thirty-four subjects with IPF ( 22 men and 12 women), median age 68 (range 50-81) y were prospectively studied. At baseline, all subjects were assessed with CPET and were followed up for 40 months from baseline. Receiver operating characteristic curve analysis was conducted to determine cut-off points of CPET variables for mortality, Cox regression analysis for survival using a log-rank test, and hazard ratio for death using a Wald test. RESULTS: Peak work rate $<62$ watts $(P=.005)$, peak $\dot{\mathrm{V}}_{\mathrm{O}_{2}} \leq 13.8 \mathrm{~mL} / \mathrm{kg} / \mathrm{min}(P=.031)$, tidal volume reserve $\leq 0.48 \mathrm{~L} / \mathrm{breath}(P=.010)$, minute ventilation to carbon dioxide $\left.\left(\dot{\mathrm{V}}_{\mathrm{E}}\right) / \dot{\mathrm{V}}_{\mathbf{C O}}\right)$ ratio at the anaerobic threshold $>34(P=.02)$, and $\left.\dot{\mathrm{V}}_{\mathrm{E}}\right) / \dot{\mathrm{V}}_{\mathrm{O}_{2}}$ nadir $>34(P=.002)$ were detected as cut-off points associated with mortality. Non-survivor subjects were characterized by higher dyspnea levels, the presence of pulmonary hypertension assessed by echocardiography, pronounced inefficient ventilatory pattern, lower exercise capacity, and more severe desaturation during physical exertion. By the end of the study, 11 subjects (7 women and 4 men) died. Overall mean survival was 60\%, 33.7 months (95\% CI 30.2-37.2). CONCLUSIONS: This study provides simple, practical, and novel cut-off points for CPET as predictors of prognosis to identify high-risk IPF subjects. Impairment in exercise capacity and abnormal ventilatory responses during CPET were associated with poorer survival in IPF subjects. The findings suggest considering the use of CPET for IPF risk stratification and prediction of prognosis. (ClinicalTrials.gov registration NCT01499745.) Key words: cardiopulmonary exercise testing, survival, prognostic predictors, ventilatory response, exercise intolerance. [Respir Care 2016;61(8):1100-1109. (c) 2016 Daedalus Enterprises]
\end{abstract}

\section{Introduction}

Idiopathic pulmonary fibrosis (IPF) is a chronic, progressive interstitial lung disease with substantial morbidity

Drs Vainshelboim, Fox, and Kramer are affiliated with the Pulmonary Institute, Rabin Medical Center, Beilinson Hospital, Petach Tikva, Israel. Drs Vainshelboim and Oliveira are affiliated with the Research Center in Physical Activity, Health and Leisure (CIAFEL), Faculty of Sport, University of Porto, Porto, Portugal. Drs Fox and Kramer are affiliated with the Sackler Faculty of Medicine, Tel Aviv University, Tel Aviv, Israel.

The authors have disclosed no conflicts of interest.

Correspondence: Baruch Vainshelboim PhD, Pulmonary Institute, Rabin and mortality and poor prognosis. ${ }^{1}$ IPF is characterized by progressive worsening of lung function and dyspnea, impaired gas exchange, inefficient breathing pattern, exercise-induced hypoxemia, and exercise intolerance. ${ }^{1,2} \mathrm{Me}-$ dian survival has been reported between 2 and 3 y from the time of diagnosis. However, more recent data suggest that this might be underestimated, and some patients live much longer. ${ }^{1,3}$

Medical Center, Beilinson Hospital, Petach Tikva 49100, Israel. Tel.: 9723-9377221/3; Fax: 972-3-9242091; E-mail: baruch.v1981@ gmail.com.

DOI: $10.4187 /$ respcare.04471 
Although IPF has an overall poor prognosis, the clinical course for individual patients varies from slow progression to acute decompensation and death. ${ }^{4}$ The heterogeneity of the clinical course in IPF makes it difficult to predict the disease outcome and, hence, the optimal timing for lung transplantation. ${ }^{5}$ Moreover, patients with IPF present the highest waiting list mortality among lung transplantation candidates, ranging widely from 14 to $67 \% .^{6}$

Several prognostic variables have been shown to correlate with survival. ${ }^{1,7}$ However, there is no established method of combining these predictors to accurately determine prognosis, and research in this area has failed to yield prediction models that can be reliably used in clinical practice to predict individual risk of mortality. ${ }^{3}$

Cardiopulmonary exercise testing (CPET) is a reliable, accurate, and valid tool and is considered the accepted standard measurement for cardio-respiratory capacity (peak $\dot{\mathrm{V}}_{\mathrm{O}_{2}}$ ) and exercise limitations. ${ }^{8-13}$ Peak $\dot{\mathrm{V}}_{\mathrm{O}_{2}}$ is a well-established universal prognostic parameter that represents the physiological capacity of the heart, lungs, and skeletal muscles to supply aerobically the metabolic demand for the body's physical functioning. ${ }^{11,12}$ In the past few decades, ventilatory efficiency parameters, such as the ratio of ventilation to carbon dioxide slope and the ratio of ventilation to carbon dioxide at the anaerobic threshold $\left(\dot{\mathrm{V}}_{\mathrm{E}} / \dot{\mathrm{V}}_{\mathrm{CO}_{2}}\right.$ at the anaerobic threshold) have also showed strong prognostic value in many chronic conditions, including IPF. ${ }^{10-15}$ In patients with IPF, abnormal multifactorial pathophysiology and exercise limitations are usually represented during CPET. ${ }^{16,17}$ These may include exercise intolerance, cardiovascular compromises, inefficient ventilation, and desaturation, which are common impairments in physical exertion. ${ }^{16-18}$

CPET has some ameliorated prognostic value compared with resting cardiopulmonary functions both in cardiac and lung disease patients. ${ }^{8-13} \mathrm{~A}$ few studies have shown several CPET parameters as prognostic predictors in subjects with IPF as well. ${ }^{14,15,19,20}$ However, these studies have significant limitations in terms of retrospective methodology, ${ }^{14}$ low sensitivity level, ${ }^{19}$ and challenging implementation in clinical practice, due to complicity and lack of availability. ${ }^{20}$ Considering these gaps in the currently available data, we aimed to identify practical prognostic predictors of mortality using cardiopulmonary exercise testing in subjects with IPF.

\section{Methods}

\section{Subjects and Setting}

This observational prospective follow-up study was conducted at the Pulmonary Institute, Rabin Medical Center, Beilinson Hospital, Petach-Tikva, Israel, and was approved by the hospital ethics committee. Written informed consent was obtained from each subject before participation. Subjects were included if diagnosed with IPF according to

\section{QUICK LOOK}

\section{Current knowledge}

Cardiopulmonary exercise testing (CPET) is a wellestablished prognostic tool in several cardiac and lung diseases, especially heart failure and pulmonary hypertension. Idiopathic pulmonary fibrosis is a chronic unpredictable fatal lung disease in which CPET has limited prognostic reliable and practical outcomes.

\section{What this paper contributes to our knowledge}

This study determines several new, noninvasive, simple, and practical CPET variable cut-off points related to exercise intolerance and inefficient ventilation that can provide prognostic utility, risk stratification, and assistance with clinical decision making in patients with idiopathic pulmonary fibrosis.

accepted clinico-radiological criteria of the American Thoracic Society and European Respiratory Society and were clinically stable in the previous 3-6 months. ${ }^{1}$ Exclusion criteria were: severe co-morbid illnesses, unstable cardiac disease, and any neurological or orthopedic contraindications for exercise testing.

In the current study, subjects from our previous exercise training study ${ }^{21}$ were followed up until 40 months from baseline. Thirty-eight IPF patients treated in the Pulmonary Institute were screened for eligibility to participate in the study. ${ }^{22}$ According to $50-\mathrm{m}$ improvement in 6-min walk distance, a power analysis before the recruitment revealed that a total of 30 participants were needed (15 in each group) to detect a significant difference between the groups. ${ }^{21,22}$ Thirty-four subjects volunteered and were recruited based on a $10 \%$ expected dropout rate in a previous exercise training study in ILD. ${ }^{23}$ Demographic characteristics were obtained from all subjects, and evaluation for dyspnea by the Modified Medical Research Council scale was made. ${ }^{24,25}$ During the subjects' visit at the clinic, randomization was performed by a study coordinator uninvolved in subjects' assessment or treatment. Sealed envelopes containing each subject's intervention allocation were randomly opened, and the subject was assigned to either an exercise training group $(n=16)$, where the subject participated in a 60-min, twice weekly, supervised exercise program for 12 weeks, or a control group $(n=18)$, where the subject continued with the usual care alone. ${ }^{21}$ In the current study, baseline data of subjects in both groups $(n=34)$ were used to determine the prognostic predictors of survival. Subjects were tested as described below and followed up for 40 months from baseline. 


\section{Doppler Echocardiography}

Two-dimensional echocardiography was performed at rest according to the American Society of Echocardiography guidelines (Vivid 7 Dimension, GE Healthcare, Madison, Wisconsin). ${ }^{26}$ Systolic pulmonary arterial pressure was estimated from the maximal tricuspid regurgitated jet velocity adding estimated right atrial pressure. ${ }^{27}$ Pulmonary hypertension was defined as systolic pulmonary arterial pressure $>35 \mathrm{~mm} \mathrm{Hg}$. Mild to moderate pulmonary hypertension was defined as systolic pulmonary arterial pressure between 35 and $50 \mathrm{~mm} \mathrm{Hg}$, and severe pulmonary hypertension was defined as systolic pulmonary arterial pressure $>50 \mathrm{~mm} \mathrm{Hg.}{ }^{28}$ Left ventricular systolic function was determined using standard techniques. ${ }^{26}$

\section{Pulmonary Function Tests}

Pulmonary function tests, including spirometry total lung capacity and maximal voluntary ventilation, and diffusion capacity for carbon monoxide, were performed according to standard techniques and American Thoracic Society/European Respiratory Society guidelines (Zan 530, nSpire, Oberthulba, Germany). ${ }^{29-31}$ All of the measured parameters were presented as percentage of predicted values of the European Community for Coal and Steel. ${ }^{32}$

\section{CPET}

CPET was performed according to established guidelines on an electromagnetically braked cycle ergometer using a 10-15 watts/min ramp protocol (Ergoline $\mathrm{GmbH}$ 800S, Lindenstrasse 572475 Bitz, Germany) with metabolic chart of breath-by-breath respiratory gas exchange, 12-lead electrocardiogram, blood pressure cuff, and pulse oximetry $\left(\mathrm{S}_{\mathrm{pO}_{2}}\right)$ (Zan 600, nSpire, Oberthulba, Germany). ${ }^{8,9,12,33}$ Subjects were instructed to take their usual medications as prescribed. All tests were conducted between 8:30 a.m. and 12:30 p.m. to maximal subjective exertion level and respiratory exchange ratio $(\geq 1.1)$ and were supervised by a physician. ${ }^{12}$ Cardiopulmonary data were calculated and analyzed based on an average of 30-s presentation. The anaerobic threshold was determined by the dual-method approach, using the $\mathrm{V}$-slope method combining ventilatory equivalents $\left(\dot{\mathrm{V}}_{\mathrm{E}} / \dot{\mathrm{V}}_{\mathrm{O}_{2}}\right.$ and $\left.\dot{\mathrm{V}}_{\mathrm{E}} / \dot{\mathrm{V}}_{\mathrm{CO}_{2}}\right){ }^{12}$ $\dot{\mathrm{V}}_{\mathrm{E}} / \dot{\mathrm{V}}_{\mathrm{O}_{2}}$ nadir was defined as the lowest value of $\dot{\mathrm{V}}_{\mathrm{E}} / \dot{\mathrm{V}}_{\mathrm{O}_{2}}$ ratio during the exercise. ${ }^{14,15,19,20}$ A novel respiratory parameter, tidal volume reserve, which assesses tidal volume response and ventilatory efficiency during exercise, was calculated from CPET; tidal volume reserve was defined as the peak tidal volume minus the resting tidal volume. CPET parameters were compared with normal values proposed by Wasser$\operatorname{man}^{34}$ and also expressed as percentage predicted.

\section{6-Min Walk Test}

The 6-min walk test was conducted according to American Thoracic Society guidelines in a 35-m corridor at the pulmonary unit within the hospital. ${ }^{35}$ Borg dyspnea category-ratio 10 scale, heart rate, and oxygen saturation $\left(\mathrm{S}_{\mathrm{pO}_{2}}\right.$; pulse oximeter 250030 EM, Nonim Medical, Minneapolis, Minnesota) were obtained before and immediately after the test. ${ }^{33}$

\section{Exercise Training Program}

The program was conducted according to general exercise training recommendations for respiratory disease patients. ${ }^{33,36}$ The training program included aerobic, resistance, and flexibility exercise modes as well as deep breathing exercises in each session. The program continued for 12 weeks, twice weekly with 60-min group exercise training in the pulmonary unit. The program was divided into two 6-week exercise progressive blocks, in which the overall load was gradually increased according to the subject's tolerance. In the first block, interval training was used for the aerobic component, and a single set system was used for the resistance and flexibility components. In the second block, aerobic endurance and a multiple set system were implemented. A more detailed description of the exercise program can be found in our previous report. ${ }^{21}$

\section{Primary and Secondary Outcomes}

Based on previously established prognostic CPET data in heart and lung disease ${ }^{8-13}$ as well as in patients with IPF, ${ }^{14,15,19,20}$ the primary outcomes of the current study were peak $\dot{\mathrm{V}}_{\mathrm{O}_{2}}$, peak work rate, $\dot{\mathrm{V}}_{\mathrm{E}} / \dot{\mathrm{V}}_{\mathrm{O}_{2}}$ nadir, anaerobic threshold $\dot{\mathrm{V}}_{\mathrm{E}} / \mathrm{V}_{\mathrm{CO}}$, and tidal volume reserve cut-off points using CPET in subjects with IPF. The secondary outcome was characterizing non-survivor subjects with IPF.

\section{Statistical Analysis}

Demographic, clinical, and physiological data of the participants are presented as median (range). Categorical variables are presented in $n(\%)$. Comparison between survivors and non-survivors was performed by MannWhitney $\mathrm{U}$ test for non-normally distributed parameters and chi-square test for categorical variables. Receiver operating characteristic curve analysis for cut-off points with $>70 \%$ sensitivity and $>60 \%$ specificity to detect mortality was performed for exercise capacity (peak $\dot{\mathrm{V}}_{\mathrm{O}_{2}}$, peak work-rate) and ventilatory efficiency variables $\left(\mathrm{V}_{\mathrm{E}} / \dot{\mathrm{V}}_{\mathrm{O}_{2}}\right.$ nadir, anaerobic threshold $\dot{\mathrm{V}}_{\mathrm{E}} / \dot{\mathrm{V}}_{\mathrm{CO}_{2}}$, and tidal volume reserve) as was previously demonstrated. ${ }^{14,15,19,20}$ Cox regression analysis using a log-rank test was conducted for survival analysis and comparison between significant cut- 
Table 1. Demographic Characteristics and Cardiopulmonary Variables of Study Population

\begin{tabular}{|c|c|}
\hline Variables & Values \\
\hline Age, median (range) y & $68(50-81)$ \\
\hline Male/female sex, $n(\%)$ & $22 / 12(65 / 35)$ \\
\hline Body mass index, median (range) $\mathrm{kg} / \mathrm{m}^{2}$ & $29(22-37)$ \\
\hline Time from diagnosis, median (range) y & $1(0.1-15)$ \\
\hline Subjects with smoking history, $n(\%)$ & $20(59)$ \\
\hline Pack-years, median (range) & $27(0-112)$ \\
\hline \multicolumn{2}{|l|}{ Supplemental oxygen users, $n(\%)$} \\
\hline Rest & $4(12)$ \\
\hline Exertion & $9(26)$ \\
\hline \multicolumn{2}{|l|}{ Co-morbidities, $n(\%)$} \\
\hline $\begin{array}{l}\text { Pulmonary hypertension according to } \\
\text { echocardiography }\end{array}$ & $13(38)$ \\
\hline Coronary artery disease & $14(41)$ \\
\hline Systemic hypertension & $24(71)$ \\
\hline COPD-emphysema & $8(24)$ \\
\hline Type 2 diabetes & $13(38)$ \\
\hline Osteoporosis & $5(15)$ \\
\hline \multicolumn{2}{|l|}{ Medications, $n(\%)$} \\
\hline Corticosteroids & $23(68)$ \\
\hline Pirfenidone & $3(9)$ \\
\hline$\beta$ blockers & $13(38)$ \\
\hline \multicolumn{2}{|l|}{ MMRC $(0-4), n(\%)$} \\
\hline 0 & $1(3)$ \\
\hline 1 & $14(41)$ \\
\hline 2 & $8(24)$ \\
\hline 3 & $10(29)$ \\
\hline 4 & $1(3)$ \\
\hline \multicolumn{2}{|l|}{$\begin{array}{l}\text { Resting cardiopulmonary parameters, } \\
\text { median (range) }\end{array}$} \\
\hline FVC, $\%$ predicted & $68(37-109)$ \\
\hline $\mathrm{FEV}_{1}, \%$ predicted & $70(35-124)$ \\
\hline TLC, $\%$ predicted & $64(35-99)$ \\
\hline $\mathrm{D}_{\mathrm{LCO}}, \%$ predicted & $50(23-91)$ \\
\hline $\mathrm{MVV}, \mathrm{L} / \mathrm{min}$ & $73(32-136)$ \\
\hline $\mathrm{S}_{\mathrm{pO}_{2}}$ at rest, $\%$ & $97(87-99)$ \\
\hline Ejection fraction, $\%$ & $60(43-70)$ \\
\hline Cardiac output, L/min & $5(3.6-8)$ \\
\hline Stroke volume, $\mathrm{mL} / \mathrm{beat}$ & $71(43-115)$ \\
\hline Systolic pulmonary arterial pressure, $\mathrm{mm} \mathrm{Hg}$ & $30(23-53)$ \\
\hline \multicolumn{2}{|l|}{ Exercise tolerance } \\
\hline$\dot{\mathrm{V}}_{\mathrm{O}_{2}}$ peak, $\mathrm{mL} / \mathrm{kg} / \mathrm{min}$ & $13.7(8-22)$ \\
\hline$\dot{\mathrm{V}}_{\mathrm{O}_{2}}$ peak, $\%$ predicted & $62(35-91)$ \\
\hline Anaerobic threshold, $\mathrm{mL} / \mathrm{kg} / \mathrm{min}$ & $10(7-15)$ \\
\hline Peak $\dot{\mathrm{V}}_{\mathrm{O}_{2}}, \%$ predicted & $42(27-78)$ \\
\hline Peak work rate & $69(35-136)$ \\
\hline Peak work rate, $\%$ predicted & $51(27-92)$ \\
\hline $6 \mathrm{MWD}, \mathrm{m}$ & $505(130-749)$ \\
\hline $6 \mathrm{MWD}, \%$ predicted & $99(35-147)$ \\
\hline $\begin{array}{l}n=34 . \\
\text { MMRC }=\text { Modified Medical Research Council Dyspnea Scale } \\
\text { TLC = total lung capacity } \\
\mathrm{D}_{\mathrm{LCO}}=\text { diffusion capacity for carbon monoxide } \\
\text { MVV = maximal voluntary ventilation } \\
\text { Peak } \dot{\mathrm{V}}_{\mathrm{O}_{2}}=\text { peak oxygen consumption } \\
6 \mathrm{MWD}=6 \text {-min walk distance. }\end{array}$ & \\
\hline
\end{tabular}

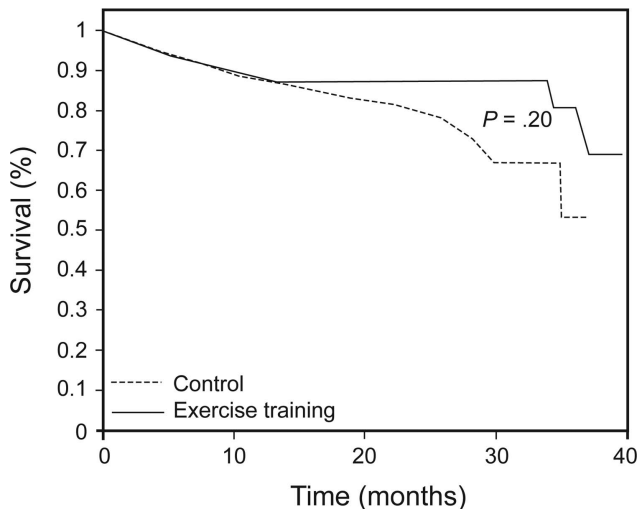

Fig. 1. Comparison of Kaplan-Meir survival curves between exercise training and control groups.

off points as well as between the exercise training and control groups at the 40-month time point. Hazard ratio for death or lung transplantation using a Wald test was calculated based on variables' cut-off points that were identified as significant in the receiver operating characteristic analysis. Subjects who underwent lung transplants were considered as fatalities in the statistical analysis, as has been reported previously. ${ }^{5,14}$ Exploratory data analysis using Spearman's correlation coefficient ${ }^{37}$ was performed between the previously demonstrated ${ }^{1}$ and the proposed prognostic predictors in the current study. The statistical analyses were conducted using SPSS 17 (SPSS, Chicago, Illinois). The significance level was set at $P<.05$.

\section{Results}

The study population consisted of 34 IPF subjects from the Pulmonary Institute who were recruited for pulmonary rehabilitation. ${ }^{21}$ All subjects completed the tests without adverse events. Demographic, cardiopulmonary, and exercise data are presented in Table 1. After recruitment, subjects were randomly allocated to the exercise training group $(n=16)$ and participated in 12-week, 60-min twice weekly supervised exercise sessions or to the control group $(n=18)$ and continued regular medical care. During the follow-up period, 5 subjects in the control group and 3 subjects in the exercise training group were treated with pirfenidone, without any significant differences between the groups for the number of pirfenidone users $(P=.54)$. There were no other changes in medications during the study period.

During the 40-month study, 11 subjects died (7 women and 4 men). Two of the 11 subjects were at end-stage IPF and underwent lung transplantation and were considered as fatalities in the analysis. We have reported previously that at 30-month follow-up, group allocation does not affect survival or hospitalization in this group of subjects..$^{38}$ However, that study was underpowered to detect such changes. ${ }^{38}$ There was no significant difference between 


\section{VeNTILATORY INEFFICIENCY AND EXERCISE CAPACITY IN IPF}

Table 2. Cut-Off Points Predicting Mortality Using Cardiopulmonary Exercise Testing, Pulmonary Function, and 6-Min Walk Test Among Subjects With Idiopathic Pulmonary Fibrosis

\begin{tabular}{|c|c|c|c|c|}
\hline Cut-Off Point for Parameters & AUC $(95 \%$ CI) & Sensitivity, $\%$ & Specificity, $\%$ & $P$ \\
\hline Peak work rate $<62$ watts & $0.854(0.73-0.98)$ & 82 & 78 & .001 \\
\hline Peak $\dot{\mathrm{V}}_{\mathrm{O}_{2}} \leq 13.8 \mathrm{~mL} / \mathrm{kg} \min$ & $0.731(0.56-0.9)$ & 82 & 61 & .031 \\
\hline Tidal volume reserve $\leq 0.48 \mathrm{~L} /$ breath & $0.810(0.66-0.96)$ & 82 & 78 & .004 \\
\hline Nadir $\dot{\mathrm{V}}_{\mathrm{E}} / \dot{\mathrm{V}}_{\mathrm{O}_{2}}>34$ & $0.736(0.56-0.9)$ & 78 & 84 & .031 \\
\hline$\dot{\mathrm{V}}_{\mathrm{E}} / \dot{\mathrm{V}}_{\mathrm{CO}_{2}}$ at $\mathrm{AT}>34$ & $0.783(0.6-0.96)$ & 73 & 74 & .008 \\
\hline$\%$ predicted $\mathrm{FVC}<60$ & $0.524(0.28-0.77)$ & 46 & 78 & .83 \\
\hline$\%$ predicted $\mathrm{D}_{\mathrm{LCO}} \leq 48$ & $0.787(0.62-0.96)$ & 81 & 77 & .008 \\
\hline $6 \mathrm{MWD}<500 \mathrm{~m}$ & $0.757(0.58-0.94)$ & 72 & 63 & .020 \\
\hline $\mathrm{S}_{\mathrm{pO}_{2}}$ post- $6 \mathrm{MWT}<85 \%$ & $0.826(0.68-0.97)$ & 82 & 78 & .002 \\
\hline \multicolumn{5}{|c|}{$\begin{array}{l}\text { AUC }=\text { area under the curve } \\
\text { Peak } \dot{V}_{\mathrm{O}_{2}}=\text { peak oxygen consumption } \\
\text { Peak } \dot{\mathrm{V}}_{\mathrm{E}} / \dot{\mathrm{V}}_{\mathrm{O}_{2}}=\text { ventilatory equivalent for oxygen consumption } \\
\dot{\mathrm{V}}_{\mathrm{E}} / \dot{\mathrm{V}}_{\mathrm{CO}_{2}} \text { at AT }=\text { ventilatory equivalent for carbon dioxide at the anaerobic threshold point } \\
\mathrm{D}_{\mathrm{LCO}}=\text { diffusion capacity for carbon monoxide } \\
6 \mathrm{MWD}=6 \text {-min walk distance } \\
6 \mathrm{MWT}=6 \text {-min walk test }\end{array}$} \\
\hline
\end{tabular}

the exercise training and the control groups in the number of subjects who continued or started a 12-week pulmonary rehabilitation program during the follow-up period $(P=.56)$. In the current study, consistent with our previous report, no significant difference was found between the exercise training and control groups in survival at 40month follow-up $(P=.20)$ (Fig. 1).

Significant cut-off points from CPET variables were determined as prognostic predictors using receiver operating characteristic analysis (Table 2). Subjects had poorer survival with significantly increased risk for mortality if they presented with a peak work rate $<62$ watts $(P=.005)$; peak $\dot{\mathrm{V}}_{\mathrm{O}_{2}} \leq 13.8 \mathrm{~mL} / \mathrm{kg} / \mathrm{min}(P=.031)$; tidal volume reserve $\leq 0.48 \mathrm{~L} / \mathrm{breath}(P=.01)$; anaerobic threshold $\dot{\mathrm{V}}_{\mathrm{E}} / \dot{\mathrm{V}}_{\mathrm{CO}_{2}}>34(P=.02)$, and $\dot{\mathrm{V}}_{\mathrm{E}} / \dot{\mathrm{V}}_{\mathrm{O}_{2}}$ nadir $>34(P=.002)$ (Figs. 2 and 3 and Tables 2 and 3). Non-survivor subjects were characterized by the presence of pulmonary hypertension with a higher systolic pulmonary arterial pressure, a lower level of 6-min walk distance, more severe desaturation during exercise, higher dyspnea levels, and ventilatory inefficiency (Table 4). Overall mean survival was 60\%, 33.7 (95\% CI 30.2-37.2) months (see Fig. 3). Exploratory analysis of previously established and current prognostic predictors showed significant correlations, especially between 6-min walk distance and CPET variables (Table 5).

\section{Discussion}

In this prospective observational follow-up study, we aimed to identify prognostic predictors of mortality using CPET among IPF subjects. We detected significant cut-off points of exercise capacity and ventilatory responses predicting mortality in subjects with IPF (Tables 2 and 3). We also found that non-survivor subjects were characterized by a higher prevalence of pulmonary hypertension, a lower level of exercise capacity, more severe desaturation, and higher dyspnea levels with evident breathing inefficiency compared with survivors (Table 4). Consistent with our previous report, ${ }^{38}$ the current study did not show benefits in survival following exercise training intervention at 40month follow-up (see Fig. 1), although this study was underpowered to detect such differences. Furthermore, the study showed good correlations between the new CPET and previously established prognostic variables in IPF (Table 5), which strengthens our findings. These data emphasize the utility and the valuable role of CPET for risk stratification. CPET also can be a practical aid in clinical decision making and treatment, such as for lung transplantation referral and pulmonary rehabilitation, for patients with IPF.

The results of this study align with previous data suggesting that exercise capacity and ventilatory efficiency variables $\left(\dot{\mathrm{V}}_{\mathrm{E}} / \dot{\mathrm{V}}_{\mathrm{O}_{2}}\right.$ and $\left.\dot{\mathrm{V}}_{\mathrm{E}} / \dot{\mathrm{V}}_{\mathrm{CO}_{2}}\right)$ are associated with survival in IPF. ${ }^{14,15,19,20}$ However, the present study adds several new practical cardiopulmonary parameters (peak work rate and tidal volume reserve) and cut-off points that can be considered as good prognostic predictors in IPF. Moreover, this study overcame some of the gaps and methodological limitations that exist in previous publications ${ }^{14,15,19,20}$ by adopting a prospective follow-up, using sensitive thresholds for variables, reporting both the levels of sensitivity and specificity, characterizing non-survival subjects, and indicating the hazard ratios for death (Tables 2 and 4). This comprehensive approach enables the clinician to make more confident decisions with respect to risk stratification, treatment options, and prognosis of patients with IPF, as supported by several previous studies in 

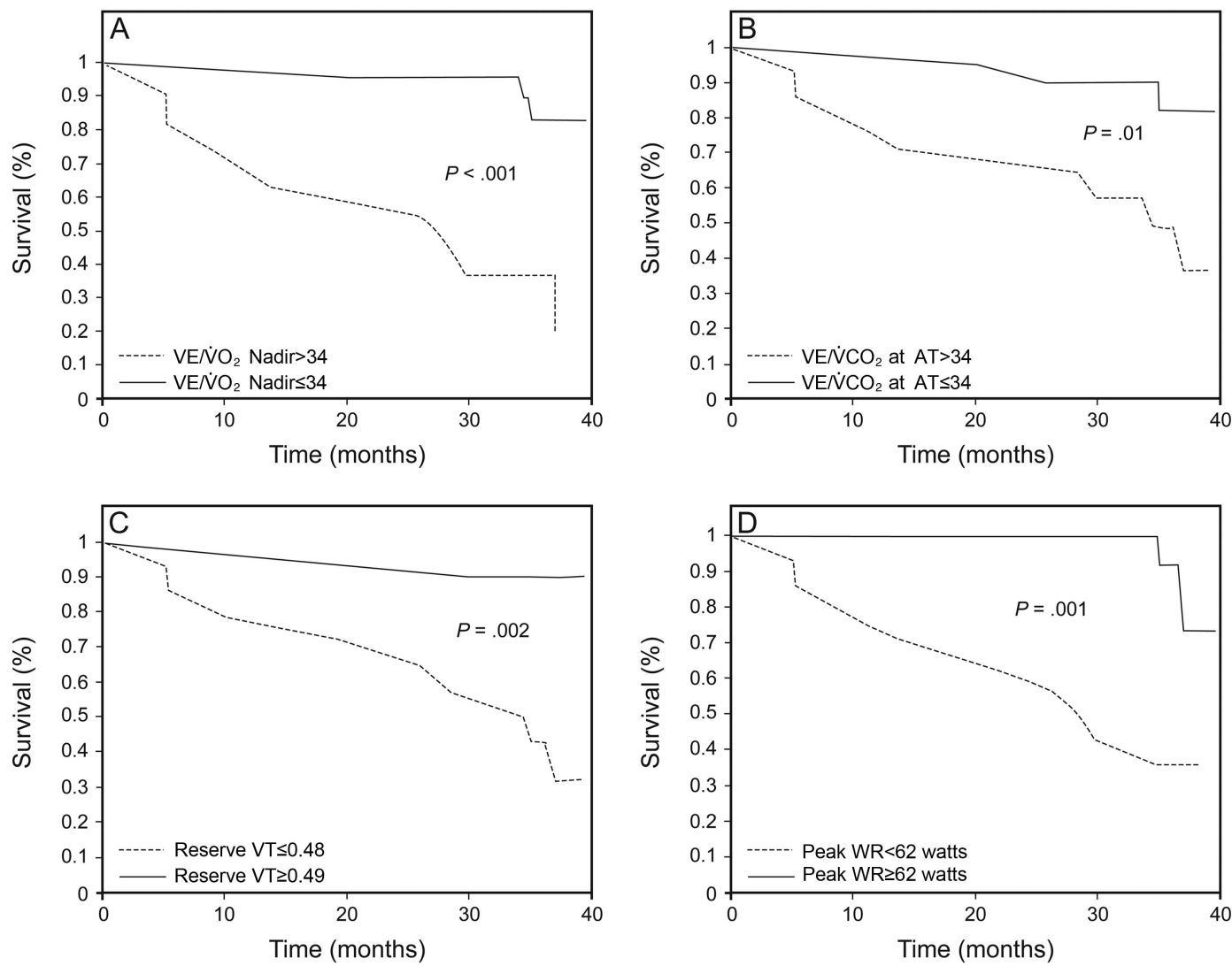

Fig. 2. Kaplan-Meir survival curves of cardiopulmonary exercise test variables in subjects with idiopathic pulmonary fibrosis. VT $=$ tidal volume. $\mathrm{WR}=$ work rate.
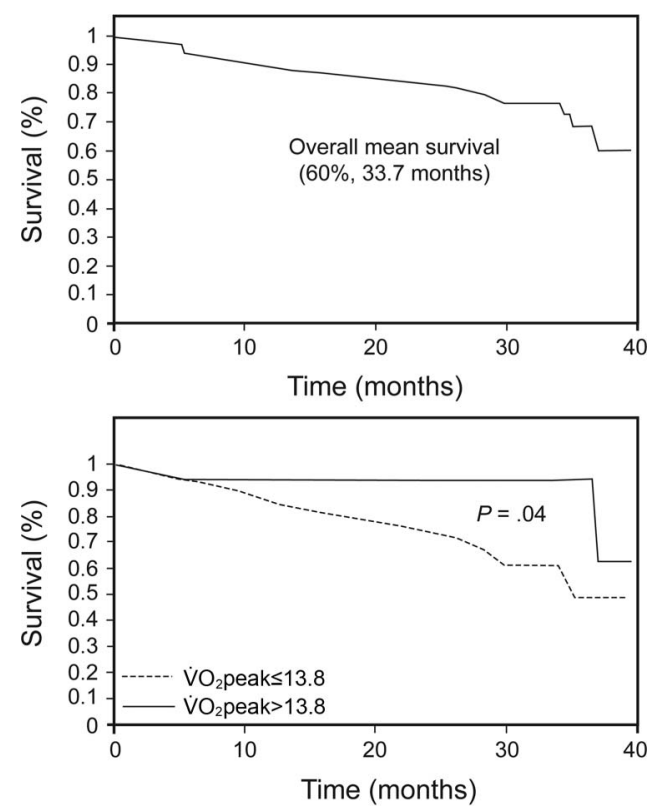

Fig. 3. Kaplan-Meir curves of overall survival and peak oxygen consumption in subjects with idiopathic pulmonary fibrosis.

IPF. ${ }^{14,15,39}$ Miki et $\mathrm{al}^{20}$ retrospectively showed that $\Delta \mathrm{P}_{\mathrm{aO}_{2}} / \Delta \dot{\mathrm{V}}_{\mathrm{O}_{2}}\left(\mathrm{P}_{\mathrm{aO}_{2}}\right.$ slope $) \leq 60 \mathrm{~mm} \mathrm{Hg} / \mathrm{L} /$ min during CPET was the most useful tool to predict mortality in 41 subjects with IPF. ${ }^{20}$ Although $\mathrm{P}_{\mathrm{aO}}$ slope was shown as a good predictor of mortality, it is rarely calculated and implemented in daily practice. This is because this measure requires an invasive sophisticated procedure of arterial blood gas analysis during the exercise test, which in most clinical exercise laboratories is unavailable. Fell et $\mathrm{al}^{19}$ also retrospectively showed a threshold of 8.3 $\mathrm{mL} / \mathrm{kg} / \mathrm{min}$ in peak $\dot{\mathrm{V}}_{\mathrm{O}_{2}}$ to predict survival of $117 \mathrm{IPF}$ subjects, ${ }^{19}$ whereas Triantafillidou et al ${ }^{15}$ prospectively demonstrated a threshold of $14.2 \mathrm{~mL} / \mathrm{kg} / \mathrm{min}$ for survival among 25 subjects with IPF. ${ }^{15}$ Despite the fact that peak $\dot{\mathrm{V}}_{\mathrm{O}_{2}}$ has been shown as an accurate and reliable prognostic predictor in many cardiopulmonary diseases, ${ }^{8-10}$ in Fell's study, ${ }^{19}$ only 8 subjects $(6.83 \%)$ were below the $8.3 \mathrm{~mL} / \mathrm{kg} / \mathrm{min}$ threshold, but about $46 \%$ died, which make this threshold much less sensitive. ${ }^{19}$ Furthermore, a threshold of $14.2 \mathrm{~mL} / \mathrm{kg} / \mathrm{min}$ seems to have a good sensitivity in predicting mortality based on the report of Triantafillidou et al. ${ }^{15}$ However, their findings are limited by a small sample size and so cannot be generalized, as well as contradicting previous reports..$^{19,20} \mathrm{In}$ our cohort, a peak $\dot{\mathrm{V}}_{\mathrm{O}_{2}}$ cut-off point of $13.8 \mathrm{~mL} / \mathrm{kg} / \mathrm{min}$ was also found to be a significant prognostic predictor, which is in line with the results of Triantafillidou et al. ${ }^{15}$ (Table 2). Nevertheless, the prognostic role of peak $\dot{\mathrm{V}}_{\mathrm{O}_{2}}$ in IPF still needs to be ascertained in a large prospective study. 


\section{Ventilatory INEFFICIENCY AND EXERCISE CAPACITY IN IPF}

Table 3. Survival Data and Bivariate Analysis of Hazard Ratio Using Cardiopulmonary Exercise Testing in 34 Idiopathic Pulmonary Fibrosis Subjects

\begin{tabular}{|c|c|c|c|c|c|c|c|}
\hline \multirow{3}{*}{ Parameters } & \multicolumn{4}{|c|}{ Survival } & \multirow{3}{*}{$\begin{array}{l}P \\
\text { Log-Rank } \\
\text { Test }\end{array}$} & \multirow{3}{*}{$\begin{array}{l}\text { Hazard Ratio } \\
\text { (95\% CI), } \\
\text { Wald Test }\end{array}$} & \multirow{3}{*}{$P$} \\
\hline & \multicolumn{2}{|c|}{ Above the Threshold } & \multicolumn{2}{|c|}{ Below the Threshold } & & & \\
\hline & $\begin{array}{c}\text { Mean } \\
(95 \% \text { CI }) \text { Months }\end{array}$ & $\begin{array}{c}\% \text { of } \\
\text { Subjects }\end{array}$ & $\begin{array}{c}\text { Mean } \\
(95 \% \text { CI) Months }\end{array}$ & $\begin{array}{c}\% \text { of } \\
\text { Subjects }\end{array}$ & & & \\
\hline Peak work rate $<62$ watts & $38.7(36.7-39.7)$ & 90 & $26.2(19.6-32.9)$ & 36 & .001 & $9.2(1.9-42.6)$ & .005 \\
\hline Peak $\dot{\mathrm{V}}_{\mathrm{O}_{2}}<13.8 \mathrm{~mL} / \mathrm{kg} \cdot \mathrm{min}$ & $36.6(32.4-40.7)$ & 82 & $30.7(25.6-35.8)$ & 50 & .040 & $4.4(0.94-20.3)$ & .060 \\
\hline Tidal volume reserve $\leq 0.48$ (L/breath) & $37.7(35-40)$ & 90 & $28.2(21.7-34.8)$ & 36 & .002 & $7.6(1.6-35.2)$ & .010 \\
\hline$\dot{\mathrm{V}}_{\mathrm{E}} / \dot{\mathrm{V}}_{\mathrm{O}_{2}}$ nadir $>34$ & $38(36.3-39.8)$ & 87 & $24.2(16.2-32.1)$ & 27 & $<.001$ & $8.3(2.2-31.6)$ & .002 \\
\hline$\dot{\mathrm{V}}_{\mathrm{E}} / \dot{\mathrm{V}}_{\mathrm{CO}_{2}}$ at $\mathrm{AT}>34$ & $37.5(35.2-39.7)$ & 85 & $28.2(21.4-35)$ & 43 & .010 & $4.6(1.2-17.3)$ & .020 \\
\hline \multicolumn{8}{|c|}{$\begin{array}{l}\text { Peak } \dot{\mathrm{V}}_{\mathrm{O}_{2}}=\text { peak oxygen consumption } \\
\dot{\mathrm{V}}_{\mathrm{E}} / \dot{\mathrm{V}}_{\mathrm{O}_{2}}=\text { ventilatory equivalent for oxygen consumption } \\
\dot{\mathrm{V}}_{\mathrm{E}} / \dot{\mathrm{V}}_{\mathrm{CO}_{2}} \text { at } \mathrm{AT}=\text { ventilatory equivalent for carbon dioxide at the anaerobic threshold point }\end{array}$} \\
\hline
\end{tabular}

Table 4. Demographic, Clinical, and Physiological Characteristics in Survivor and Non-Survivor Idiopathic Pulmonary Fibrosis Subjects

\begin{tabular}{|c|c|c|c|}
\hline Variables & Survivors $(n=23)$ & Non-Survivors $(n=11)$ & $P$ \\
\hline \multicolumn{4}{|l|}{ Demographics } \\
\hline Age, median (range) y & $68(63-72)$ & $69(55-80)$ & .75 \\
\hline Male/female sex, $n(\%)$ & $18 / 7(72 / 28)$ & $4 / 5(44 / 56)$ & .14 \\
\hline Subjects with smoking history, $n(\%)$ & $15(60 \%)$ & $5(56 \%)$ & .82 \\
\hline Pack-years, median (range) & $20(14-33)$ & $60(13-123)$ & .053 \\
\hline Emphysema, $n(\%)$ & $5(19 \%)$ & $3(43 \%)$ & .18 \\
\hline Pulmonary hypertension according to echocardiography, $n(\%)$ & $7(28 \%)$ & $6(66 \%)$ & .03 \\
\hline Systolic pulmonary arterial pressure, median (range) $\mathrm{mm} \mathrm{Hg}$ & $29(28-34)$ & $39(29-51)$ & .049 \\
\hline MMRC (0-4), median (range) & $1(1.2-1.9)$ & $3(2.1-3.4)$ & .002 \\
\hline \multicolumn{4}{|l|}{ Pulmonary function values, median (range) } \\
\hline FVC, $\%$ predicted & $70(64-77)$ & $75(42-102)$ & .31 \\
\hline $\mathrm{FEV}_{1}, \%$ predicted & $71(35-95)$ & $66(43-124)$ & .69 \\
\hline $\mathrm{D}_{\mathrm{LCO}}, \%$ predicted & $51(44-57)$ & $32(26-44)$ & .02 \\
\hline \multicolumn{4}{|l|}{ Resting echocardiography, median (range) } \\
\hline Fractioning shortening, $\%$ & $36(35-41)$ & $34(26-39)$ & .45 \\
\hline Stroke volume, $\mathrm{mL} / \mathrm{beat}$ & $72(69-82)$ & $66(54-83)$ & .87 \\
\hline \multicolumn{4}{|l|}{ Ventilatory efficiency, median (range) } \\
\hline$\dot{\mathrm{V}}_{\mathrm{E}} / \dot{\mathrm{V}}_{\mathrm{O}_{2}}$ nadir & $30(27-37)$ & $41(26-64)$ & .039 \\
\hline$\dot{\mathrm{V}}_{\mathrm{E}} / \dot{\mathrm{V}}_{\mathrm{CO}_{2}}$ at $\mathrm{AT}$ & $30(29-33)$ & $36(32-43)$ & .008 \\
\hline Tidal volume reserve, L/breath & $0.7(0.6-0.9)$ & $0.4(0.2-0.6)$ & .07 \\
\hline \multicolumn{4}{|l|}{ Exercise capacity, median (range) } \\
\hline 6MWD, m & $530(471-560)$ & $360(288-464)$ & .002 \\
\hline $\mathrm{S}_{\mathrm{pO}_{2}}$ post- $6 \mathrm{MWT}, \%$ & $87(83-90)$ & $79(73-84)$ & .008 \\
\hline Borg dyspnea scale post-6MWT $(0-10)$ & $4(3-4.7)$ & $6(4-8)$ & .049 \\
\hline Peak work rate, watts & $84(74-98)$ & $49(41-55)$ & .001 \\
\hline Peak $\dot{\mathrm{V}}_{\mathrm{O}_{2}}, \mathrm{~mL} / \mathrm{kg} / \mathrm{min}$ & $14.6(13-15.8)$ & $11.8(10-13.5)$ & .02 \\
\hline \multicolumn{4}{|l|}{$\begin{array}{l}\text { MMRC }=\text { Modified Medical Research Council Dyspnea Scale } \\
\mathrm{D}_{\mathrm{LCO}}=\text { diffusion capacity for carbon monoxide } \\
\text { Peak } \dot{\mathrm{V}}_{\mathrm{O}_{2}}=\text { peak oxygen consumption } \\
\mathrm{V}_{\mathrm{E}} / \dot{\mathrm{V}}_{\mathrm{O}_{2}}=\text { minute ventilation to oxygen consumption ratio } \\
\mathrm{V}_{\mathrm{E}} / \dot{\mathrm{V}}_{\mathrm{CO}} \text { at } \mathrm{AT}=\text { ventilatory equivalent for carbon dioxide at the anaerobic threshold point } \\
6 \mathrm{MWD}=6 \text {-min walk distance } \\
6 \mathrm{MWT}=6 \text {-min walk test }\end{array}$} \\
\hline
\end{tabular}

Possible mechanistic explanations for these findings can be related to the fact that IPF disease manifests in multifactorial limitations during exercise, which may be re- flected in some of the small variability that exists in cutoff points and different CPET variables across studies. ${ }^{16,17}$ In addition, accompanying co-morbidities, disease sever- 
Table 5. Spearman's Correlations Between Previously Established and Currently Proposed Prognostic Predictors in Idiopathic Pulmonary Fibrosis

\begin{tabular}{|c|c|c|c|c|c|c|c|c|}
\hline & \multicolumn{2}{|c|}{$\begin{array}{l}\% \text { Predicted } \\
\text { FVC }\end{array}$} & \multicolumn{2}{|c|}{$\begin{array}{c}\% \text { Predicted } \\
\mathrm{D}_{\text {LCO }}\end{array}$} & \multicolumn{2}{|c|}{ 6MWD (m) } & \multicolumn{2}{|c|}{$\begin{array}{c}\mathrm{S}_{\mathrm{pO}_{2}} \\
\text { post-6MWT (\%) }\end{array}$} \\
\hline & $\mathrm{r}$ & $P$ & $\mathrm{r}$ & $P$ & $\mathrm{r}$ & $P$ & $\mathrm{r}$ & $P$ \\
\hline Peak work rate (watts) & 0.208 & .36 & $0.447 *$ & .009 & $0.803 *$ & $<.001$ & $0.434^{*}$ & .01 \\
\hline Peak $\dot{\mathrm{V}}_{\mathrm{O}_{2}}(\mathrm{~mL} / \mathrm{kg} \min )$ & 0.161 & .36 & $0.489^{*}$ & .004 & $0.803 *$ & $<.001$ & 0.26 & .14 \\
\hline Tidal volume reserve (L/breath) & $0.380^{*}$ & .02 & $0.349^{*}$ & .047 & $0.460 *$ & .006 & $0.358^{*}$ & .038 \\
\hline$\dot{\mathrm{V}}_{\mathrm{E}} / \dot{\mathrm{V}}_{\mathrm{O}_{2}}$ nadir & 0.262 & .13 & -0.303 & .09 & $-0.379 *$ & .02 & $-0.347^{*}$ & .044 \\
\hline$\dot{\mathrm{V}}_{\mathrm{E}} / \dot{\mathrm{V}}_{\mathrm{CO}_{2}}$ at $\mathrm{AT}$ & $0.416^{*}$ & .01 & $-0.435^{*}$ & .01 & $-0.511^{*}$ & .002 & $-0.343^{*}$ & .047 \\
\hline \multicolumn{9}{|c|}{$\begin{array}{l}\text { * Significant correlation, } P<.05 \\
\mathrm{D}_{\mathrm{LCO}}=\text { diffusion capacity for carbon monoxide } \\
6 \mathrm{MWD}=6 \text {-min walk distance } \\
6 \mathrm{MWT}=6 \text {-min walk test } \\
\text { Peak } \dot{\mathrm{V}}_{\mathrm{O}_{2}}=\text { peak oxygen consumption } \\
\dot{\mathrm{V}}_{\mathrm{E}} / \dot{\mathrm{V}}_{\mathrm{O}_{2}}=\text { ventilatory equivalent for oxygen consumption } \\
\mathrm{V}_{\mathrm{E}} / \dot{\mathrm{V}}_{\mathrm{CO}_{2}} \text { at } \mathrm{AT}=\text { ventilatory equivalent for carbon dioxide at the anaerobic threshold point }\end{array}$} \\
\hline
\end{tabular}

ity, and the time course for assessment may also have an impact on differences in the reports. Most studies that assessed survival in IPF subjects suggest that exercise intolerance, exercise-induced hypoxemia and desaturation, and inefficient ventilation are associated with disease severity and poor prognosis. ${ }^{1,14-20}$ The current study also found these pathophysiological abnormalities associated with survival in IPF. It might be that the degree of fibrotic parenchymal damage manifest in restrictive pathophysiology can be detected more sensitively by exercise intolerance, abnormal pulmonary gas exchange, and inefficient ventilatory variables, especially when the physiological systems are stressed, such as during progressive CPET among IPF. Furthermore, these results demonstrated a cluster of moderate to highly significant correlations, in both resting and exercise previously established variables, ${ }^{1}$ with the prognostic predictors proposed in the current study (Table 5). This can substantially support further generalization based on the current data. However, despite these pathophysiological impairments that seem to be related to survival in patients with IPF, ${ }^{1,16-18}$ given the multifactorial nature of the disease and the diversity of predictors, we believe that prognosis should be based on a combination of predictors rather than on a single variable, and future trials should address this issue with multivariate analysis.

A few limitations exist in our study with respect to the small sample size and the level of IPF severity (FVC; 68\% predicted), so caution should be taken with generalizations. Despite these limitations, the study has several advantages in collecting data prospectively, using CPET as a reliable, accurate, and accepted standard tool for cardiorespiratory exercise evaluation, $, 8,9$ and the number of study participants in our cohort exceeded that in a previous report of CPET and prognosis. ${ }^{15}$ Moreover, the survival rates in our study were consistent with previous larger sample studies, which strengthens our findings with respect to the subjects' characteristics and increases confidence in the ability to generalize to larger IPF patient populations. ${ }^{7,19,40,41}$ In addition, although accepted standard diagnosis of pulmonary hypertension requires invasive right heart catheterization, in the current study, we used echocardiography measures, which are a well-accepted tool showing good correlation $(\mathrm{r}=0.7)$ and overall diagnostic power (sensitivity $=83 \%$, specificity $=72 \%$ ) with invasive procedures..$^{42}$ It could be argued that an additional limitation of the study is related to the subjects' group assignments for exercise training or usual care, which could have some impact on the results and potential bias. This hypothesis was rebutted in our previous ${ }^{38}$ and current reports (see Fig. 1), showing no significant differences in survival between exercise training and the control group; however, the studies were underpowered to detect survival differences.

\section{Conclusions}

This 40-month follow-up study proposes several new, noninvasive, simple, and practical CPET variable cut-off points. These are related to how exercise intolerance and inefficient ventilation can be used to predict mortality and characterization of high-risk patients with IPF. The study strengthens the evidence for using CPET to detect highrisk patients with IPF and aids in addressing appropriate treatments, such as pulmonary rehabilitation and referral for lung transplantation. We suggest considering CPET as an important evaluation tool for risk stratification and predicting prognosis for IPF. More research with a larger sample size is warranted to confirm our findings for further implementation and establishment in standard clinical practice.

\section{ACKNOWLEDGMENTS}

We thank the study coordinators, nurses, secretaries, and pulmonary function test technicians for professional assistance in the study. We 


\section{VeNTILATORY INEFFICIENCY AND EXERCISE CAPACITY IN IPF}

especially thank the echocardiography technicians for their patience, willingness to assist, and high level of professional work with the echocardiography measurements. We also thank Dalia Dawn Orkin for important English language contributions and editing services.

\section{REFERENCES}

1. Raghu G, Collard HR, Egan JJ, Martinez FJ, Behr J, Brown KK, et al. An official ATS/ERS/JRS/ALAT statement: idiopathic pulmonary fibrosis: evidence-based guidelines for diagnosis and management. Am J Respir Crit Care Med 2011;183(6):788-824.

2. Meltzer EB, Noble PW. Idiopathic pulmonary fibrosis. Orphanet J Rare Dis 2008;3:8.

3. Ley B, Collard HR, King TE Jr. Clinical course and prediction of survival in idiopathic pulmonary fibrosis. Am J Respir Crit Care Med 2011;183(4):431-440.

4. Fernández Pérez ER, Daniels CE, Schroeder DR, St Sauver J, Hartman TE, Bartholmai BJ, et al. Incidence, prevalence, and clinical course of idiopathic pulmonary fibrosis: a population-based study. Chest 2010;137(1):129-137.

5. Mura M, Porretta MA, Bargagli E, Sergiacomi G, Zompatori M, Sverzellati N, et al. Predicting survival in newly diagnosed idiopathic pulmonary fibrosis: a 3-year prospective study. Eur Respir J 2012;40(1):101-109.

6. Kistler KD, Nalysnyk L, Rotella P, Esser D. Lung transplantation in idiopathic pulmonary fibrosis: a systematic review of the literature. BMC Pulm Med 2014;14:139.

7. King TE, Jr., Tooze JA, Schwarz MI, Brown KR, Cherniack RM. Predicting survival in idiopathic pulmonary fibrosis: scoring system and survival model. Am J Respir Crit Care Med 2001;164(7):11711181.

8. Ferrazza AM, Martolini D, Valli G, Palange P. Cardiopulmonary exercise testing in the functional and prognostic evaluation of patients with pulmonary diseases. Respiration 2009;77(1):3-17.

9. ERS Task Force, Palange P, Ward SA, Carlsen KH, Casaburi R, Gallagher CG, et al. Recommendations on the use of exercise testing in clinical practice. Eur Respir J 2007;29(1):185-209.

10. Arena R, Sietsema KE. Cardiopulmonary exercise testing in the clinical evaluation of patients with heart and lung disease. Circulation 2011;123(6):668-680.

11. Balady GJ, Arena R, Sietsema K, Myers J, Coke L, Fletcher GF, et al. Clinician's Guide to cardiopulmonary exercise testing in adults: a scientific statement from the American Heart Association. Circulation 2010;122(2): 191-225.

12. American Thoracic Society, American College of Chest Physicians. Statement on cardiopulmonary exercise testing. Am J Respir Crit Care Med 2003;167(2):211-277.

13. Guazzi M, Adams V, Conraads V, Halle M, Mezzani A, Vanhees L, et al. EACPR/AHA scientific statement: clinical recommendations for cardiopulmonary exercise testing data assessment in specific patient populations. Circulation 2012;126(18):2261-2274.

14. Wallaert B, Guetta A, Wemeau-Stervinou L, Tercé G, Valette M, Nevière R, et al. [Prognostic value of clinical exercise testing in idiopathic pulmonary fibrosis]. Rev Mal Respir 2011;28(3):290296.

15. Triantafillidou C, Manali E, Lyberopoulos P, Kolilekas L, Kagouridis K, Gyftopoulos S, et al. The role of cardiopulmonary exercise test in IPF prognosis. Pulm Med 2013. doi: 10.1155/2013/514817.

16. Holland AE. Exercise limitation in interstitial lung disease: mechanisms, significance and therapeutic options. Chron Respir Dis 2010; 7(2):101-111

17. Lama VN, Martinez FJ. Resting and exercise physiology in interstitial lung diseases. Clin Chest Med 2004;25(3):435-453, v.
18. American Thoracic Society. Idiopathic pulmonary fibrosis: diagnosis and treatment. International consensus statement. American Thoracic Society (ATS), and the European Respiratory Society (ERS). Am J Respir Crit Care Med 2000;161(2 Pt 1):646-664.

19. Fell CD, Liu LX, Motika C, Kazerooni EA, Gross BH, Travis WD, et al. The prognostic value of cardiopulmonary exercise testing in idiopathic pulmonary fibrosis. Am J Respir Crit Care Med 2009; 179(5):402-407.

20. Miki K, Maekura R, Hiraga T, Okuda Y, Okamoto T, Hirotani A, Ogura T. Impairments and prognostic factors for survival in patients with idiopathic pulmonary fibrosis. Respir Med 2003;97(5): 482-490.

21. Vainshelboim B, Oliveira J, Yehoshua L, Weiss I, Fox BD, Fruchter $\mathrm{O}$, Kramer MR. Exercise training-based pulmonary rehabilitation program is clinically beneficial for idiopathic pulmonary fibrosis. Respiration 2014;88(5):378-388

22. Florey CD. Sample size for beginners. BMJ 1993;306(6886):11811184.

23. Holland AE, Hill CJ, Conron M, Munro P, McDonald CF. Short term improvement in exercise capacity and symptoms following exercise training in interstitial lung disease. Thorax 2008;63(6):549-554.

24. Mahler DA, Wells CK. Evaluation of clinical methods for rating dyspnea. Chest 1988;93(3):580-586.

25. Papiris SA, Daniil ZD, Malagari K, Kapotsis GE, Sotiropoulou C, Milic-Emili J, Roussos C. The Medical Research Council dyspnea scale in the estimation of disease severity in idiopathic pulmonary fibrosis. Respir Med 2005;99(6):755-761.

26. Schiller NB. Two-dimensional echocardiographic determination of left ventricular volume, systolic function, and mass. Summary and discussion of the 1989 recommendations of the American Society of Echocardiography. Circulation 1991;84(3 Suppl):I280-I287.

27. Schiller NB. Pulmonary artery pressure estimation by Doppler and two-dimensional echocardiography. Cardiol Clin 1990;8(2):277-287.

28. Task Force for Diagnosis and Treatment of Pulmonary Hypertension of European Society of Cardiology (ESC), European Respiratory Society (ERS), International Society of Heart and Lung Transplantation (ISHLT), Galiè N, Hoeper MM, Humbert M, et al. Guidelines for the diagnosis and treatment of pulmonary hypertension. Eur Respir J 2009;34(6):1219-1263.

29. Macintyre N, Crapo RO, Viegi G, Johnson DC, van der Grinten CP, Brusasco V, et al. Standardisation of the single-breath determination of carbon monoxide uptake in the lung. Eur Respir J 2005;26(4):720-735.

30. Miller MR, Crapo R, Hankinson J, Brusasco V, Burgos F, Casaburi $\mathrm{R}$, et al. General considerations for lung function testing. Eur Respir J 2005;26(1):153-161.

31. Wanger J, Clausen JL, Coates A, Pedersen OF, Brusasco V, Burgos $\mathrm{F}$, et al. Standardisation of the measurement of lung volumes. Eur Respir J 2005;26(3):511-522.

32. Quanjer PH, Tammeling GJ, Cotes JE, Pedersen OF, Peslin R, Yernault JC. Lung volumes and forced ventilatory flows. Report working party standardization of lung function tests, European Community for Steel and Coal: official statement of the European Respiratory Society. Eur Respir J Suppl 1993;16:5-40.

33. Pescatello LS, American College of Sports Medicine. ACSM's guidelines for exercise testing and prescription. Philadelphia: Wolters Kluwer/Lippincott Williams \& Wilkins Health; 2014.

34. Wasserman K. Principles of exercise testing and interpretation: including pathophysiology and clinical applications. Philadelphia: Lippincott Williams \& Wilkins; 2005.

35. ATS Committee on Proficiency Standards for Clinical Pulmonary Function Laboratories. ATS statement: guidelines for the six-minute walk test. Am J Respir Crit Care Med 2002;166(1):111-117.

36. Jenkins S, Hill K, Cecins NM. State of the art: how to set up a pulmonary rehabilitation program. Respirology 2010;15(8):1157-1173. 


\section{VeNTILATORY INEFFICIENCY AND EXERCISE CAPACITY IN IPF}

37. Mukaka MM. Statistics corner: A guide to appropriate use of correlation coefficient in medical research. Malawi Med J 2012;24(3):69-71.

38. Vainshelboim B, Oliveira J, Fox BD, Soreck Y, Fruchter O, Kramer MR. Long-term effects of a 12-week exercise training program on clinical outcomes in idiopathic pulmonary fibrosis. Lung 2015;193(3): 345-354.

39. Gläser S, Obst A, Koch B, Henkel B, Grieger A, Felix SB, et al. Pulmonary hypertension in patients with idiopathic pulmonary fibrosis: the predictive value of exercise capacity and gas exchange efficiency. PLoS One 2013;8(6):e65643.
40. Caminati A, Bianchi A, Cassandro R, Mirenda MR, Harari S. Walking distance on 6-MWT is a prognostic factor in idiopathic pulmonary fibrosis. Respir Med 2009;103(1):117-123.

41. du Bois RM, Albera C, Bradford WZ, Costabel U, Leff JA, Noble $\mathrm{PW}$, et al. 6-Minute walk distance is an independent predictor of mortality in patients with idiopathic pulmonary fibrosis. Eur Respir J 2014;43(5):1421-1429.

42. Janda S, Shahidi N, Gin K, Swiston J. Diagnostic accuracy of echocardiography for pulmonary hypertension: a systematic review and meta-analysis. Heart 2011;97(8):612-622. 